\title{
Climatologia do Estado do Tocantins - Brasil
}

\author{
Tocantins State Climatology - Brazil
}

\author{
Aline de Freitas Roldão \\ Doutoranda em Geografia pela \\ Universidade Federal de Uberlândia, Brasil \\ alineroldao@yahoo.com.br
}

Vanderlei de Oliveira Ferreira Doutor em Goegrafia, Professor da Universidade Federal de Uberlândia, Brasil vanderlei@ig.ufu.br

\begin{abstract}
Resumo
O presente texto descreve resultados de pesquisa dedicada à avaliação de características climáticas do Estado do Tocantins, especialmente quanto aos fatores temperatura, pluviosidade e outras variáveis do balanço hídrico climatológico. Quanto à pluviosidade, foram adotados dados diários disponibilizados pela Agência Nacional de Águas (ANA) de postos pluviométricos situados dentro e no entorno do território tocantinense para período de 32 anos (1985 a 2016). Já os dados de temperatura do ar foram obtidos a partir do projeto Reanalysis do National Centers for Environmental Prediction/National Center for Atmospheric Research (NCEP/NCAR). O cálculo do balanço hídrico foi feito através da metodologia proposta por Thornthwaite e Mather (1955), adotando-se capacidade de água disponível no solo (CAD) de $100 \mathrm{~mm}$ como valor padrão. Os tipos climáticos foram identificados de acordo com as propostas de classificação de Köppen e Geiger (1928) e Thornthwaite (1948). Espera-se que os resultados sejam úteis para a gestão territorial e pesquisas científicas em diversas áreas do conhecimento.
\end{abstract}

Palavras-chave: pluviosidade; temperatura; balanço hídrico; classificação climática.

\begin{abstract}
This paper describes research results dedicated to the evaluation of the climatic characteristics of the State of Tocantins, especially regarding the factors temperature, rainfall and other variables of the climatological water balance. Regarding rainfall, daily data provided by the Agência Nacional de Águas (ANA) were adopted from rainfall stations located in and around Tocantins territory for a period of 32 years (1985 to 2016). The air temperature data were obtained from the Reanalysis project of the National Centers for Environmental Prediction / National Center for Atmospheric Research (NCEP / NCAR). The water balance was calculated using the methodology proposed by Thornthwaite and Mather (1955), adopting the available groundwater capacity (CAD) of $100 \mathrm{~mm}$ as the default value. Climate types were identified according to the classification proposals of Köppen and Geiger (1928) and Thornthwaite (1948). The results are expected to be useful for territorial management and scientific research in various areas of knowledge.
\end{abstract}

Keywords: rainfall; temperature; hydric balance; climate classification 


\section{INTRODUÇÃO}

O aprimoramento do conhecimento acerca das características climáticas do Estado do Tocantins, especialmente temperatura do ar, pluviosidade e outras variáveis do balanço hídrico é necessário e diretamente aplicável à busca de melhor entendimento sobre as tipologias de vegetação nativa, regimes fluviais e ocupação das terras, especialmente quanto aos processos produtivos relacionados às commodities agrícolas.

Sabe-se que o Estado do Tocantins apresenta um arranjo pluviométrico bem semelhante ao verificado na região central brasileira, com um período estacional seco e outro chuvoso. A título de contextualização, a figura 1 representa o mapa da normal climatológica 1981-2010 (Precipitação acumulada anual) elaborado pelo INMET para o território brasileiro. Observa-se que o território tocantinense possui valores médios anuais de chuva entre 1250 e $2050 \mathrm{~mm}$. A maior parte do Estado recebe valores médios anuais entre 1650 e $1850 \mathrm{~mm}$. Já as porções centro-leste, sudeste e sul, possuem valores inferiores a $1650 \mathrm{~mm}$.

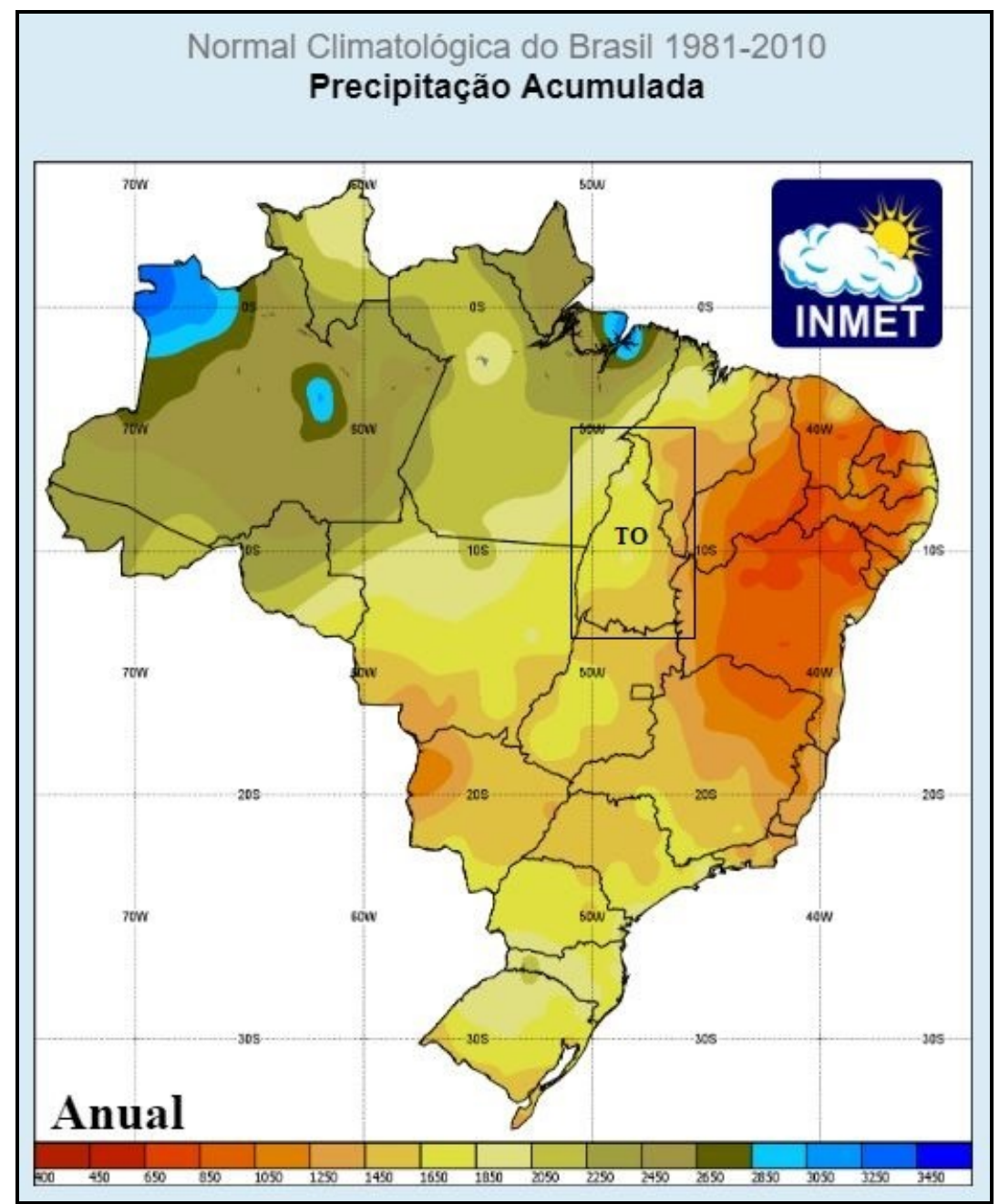

Figura 1 - Normal Climatológica do Brasil 1981-2010.

Fonte: INMET (2019) 
Os principais sistemas geradors de chuvas no Tocantins são a Zona de Convergência Intertropical (ZCIT) e a Zona de Convergência do Atlântico Sul (ZCAS). "A ZCIT é considerada o sistema mais importante gerador de precipitação sobre a região equatorial dos Oceanos Atlântico, Pacífico e Índico, assim como áreas continentais adjacentes" (MELO, et al. 2009, p.25). Tal sistema atua principalmente na porção norte do Estado do Tocantins já que, segundo Melo et al (2009), em anos chuvosos este sistema pode atingir até $5^{\circ} \mathrm{S}$, proporcionando elevados totais de precipitação.

De acordo com Hastenrath e Heller (1977) a ZCIT pode sofrer influência dos sistemas de alta pressão do Oceano Atântico. Neste caso o deslocamento das Altas Subtropicais do Atlântico Sul (ASAS) em direção ao Equador é responsável por uma menor quantidade de chuvas, enquanto que uma retração da ASAS em direção às latitudes mais altas do Atântico Sul provoca uma maior quantidade pluviométrica na região nordeste do Brasil e também na porção norte do Estado do Tocantins.

Em relação à ZCAS, de acordo com Carvalho e Jones (2009) esta se dá como uma banda de nebulosidade com orientação noroeste-sudeste sobre a América do Sul, sendo que a atividade convectiva começa no oeste da bacia amazônica, no início de agosto, e nos meses subsequentes dirige-se à região sudeste brasileira e sobre o Oceano Atlântico Subtropical.

Segundo Pegorim (2017) a ZCAS é resultante da combinação de vários sistemas meteorológicos, como as frentes frias na costa do Sudeste, o Vórtice Ciclônico de Altos Níveis no Nordeste (VCAN) e a Alta da Bolívia. Ainda de acordo com a autora os fenômenos de escala global El Niño e La Niña interferem na formação da ZCAS.

As mudanças na circulação dos ventos em diversos níveis da atmosfera causadas pelo aquecimento (El Niño) ou pelo resfriamento (La Niña) anormal das águas do oceano Pacífico Equatorial Central e Leste dificultam ou facilitam a organização da ZCAS sobre o Brasil. De forma geral, em anos de El Niño, a formação da ZCAS é dificultada, mas isto não significa que o fenômeno não ocorre. A La Niña facilita a organização da ZCAS. (PEGORIM, J. 2017)

A ZCAS atua principalmente na porção centro-sul do Tocantins, dependendo da variação de sua posição, como demonstra a figura 2. Quando a grande faixa de instabilidade forma-se numa posição mediana (1) as chuvas são mais bem distribuídas na porção sudeste do Tocantins. Já quando o eixo da ZCAS se posiciona mais ao norte as chuvas atuam em quase todo o território tocantinense, com excessão da porção norte-nordeste. 


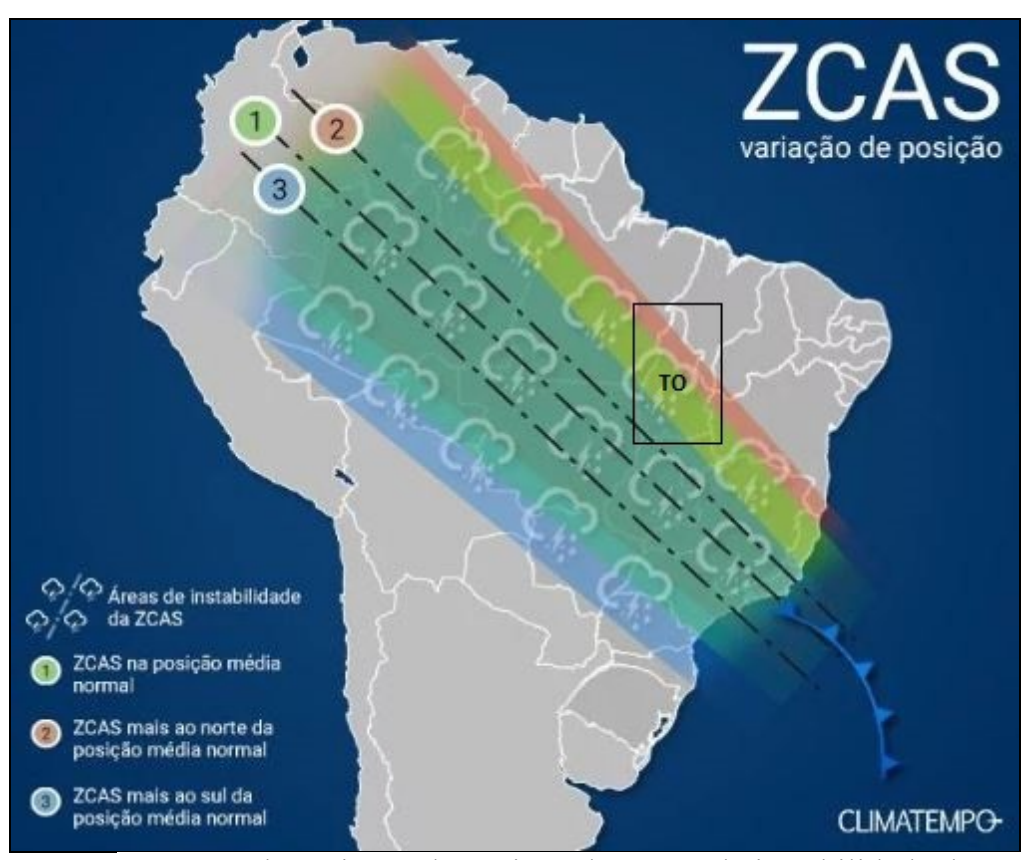

Figura 2 - Esquema de variação de posição das áreas de instabilidade da ZCAS Fonte: PEGORIM, J (2017)

É preciso conhecer melhor a distribuição das chuvas no Estado do Tocantins, considerando a escala regional e também destacando particularidades locais. É importante analisar a questão da entrada de água via pluviosidade no contexto do balanço hídrico, atentando-se para a demanda hídrica ambiental (evapotranspiração potencial), situações de deficiência e de excedentes. Neste caso, torna-se necessário levantar os dados de temperatura, necessários para estimativas da evapotranspiração. O presente artigo tem tal objetivo, aproveitando a oportunidade para apresentar informações adicionais sobre as tipologias climáticas do Estado.

\section{PROCEDIMENTOS METODOLÓGICOS}

O Estado do Tocantins está localizado na porção sudeste da região Norte brasileira, entre as longitudes $45^{\circ} \mathrm{W}$ e $51^{\circ} \mathrm{W}$ e latitudes $5^{\circ} \mathrm{S}$ e $14^{\circ} \mathrm{S}$. Tem como limites os Estados de Goiás ao sul, Mato Grosso a oeste e sudoeste, Pará a oeste e noroeste, Maranhão a norte, nordeste e leste, Piauí a leste e Bahia a leste e sudeste. (Figura 3)

A pesquisa iniciou por meio do levantamento dos dados diários de pluviosidade disponibilizados pela Agência Nacional de Águas (ANA) para um período de 32 anos (1985 a 2016). A escolha de tal período e postos pluviométricos levou em conta a menor quantidade de falhas possíveis. Foram utilizados também postos situados no entorno da área de estudo, ou seja, nos Estados de Goiás, Mato Grosso, Pará, Maranhão e Bahia. Esses dados foram necessários para o procedimento de interpolação. Os postos do interior da área de estudo somaram 56 e os do entorno somaram 27 (Quadro 1 e Figura 4). 


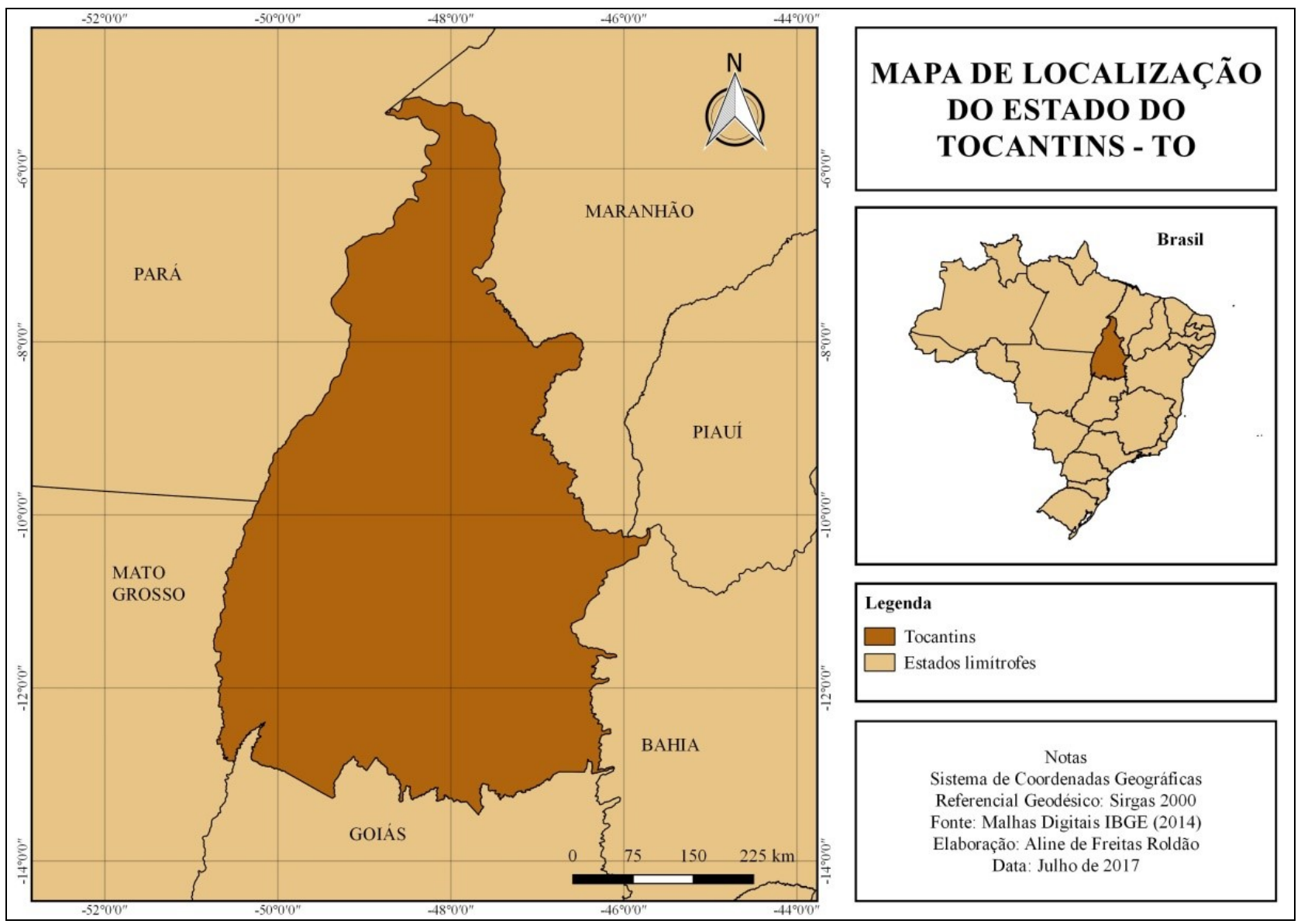

Figura 3 - Mapa de localização do Estado do Tocantins - TO.

Fonte: Malhas Digitais IBGE (2014)

Quadro 1 - Postos pluviométricos utilizados no estudo

\begin{tabular}{|c|c|c|c|c|c|c|}
\hline & \multicolumn{6}{|c|}{ Postos Pluviométricos do interior da área de estudo } \\
\hline & \multicolumn{6}{|c|}{ Estado do Tocantins (TO) } \\
\hline & Nome do Posto & Município & Código & $\begin{array}{l}\text { Latitude } \\
\text { (S) }\end{array}$ & $\begin{array}{l}\text { Longitude } \\
\text { (W) }\end{array}$ & $\begin{array}{l}\text { Altitude } \\
\text { (m) }\end{array}$ \\
\hline 1 & Almas & Almas & 1147000 & $11^{\circ} 34^{\prime} 44^{\prime \prime}$ & $47^{\circ} 10^{\prime} 26^{\prime \prime}$ & 427 \\
\hline 2 & Alvorada & Alvorada & 1249000 & $12^{\circ} 29^{\prime} 01^{\prime \prime}$ & $49^{\circ} 7^{\prime} 28^{\prime \prime}$ & 293 \\
\hline 3 & Ananas & Ananás & 648001 & $06^{\circ} 21^{\prime} 50^{\prime \prime}$ & $48^{\circ} 4^{\prime} 21^{\prime \prime}$ & 191 \\
\hline 4 & Araguacema (Chácara Araguaia) & Araguacema & 849002 & $08^{\circ} 48^{\prime} 08^{\prime \prime}$ & $49^{\circ} 33^{\prime} 20^{\prime \prime}$ & 203 \\
\hline 5 & Araguaçú & Araguaçú & 1249001 & $12^{\circ} 55^{\prime} 52^{\prime \prime}$ & $49^{\circ} 49^{\prime} 46^{\prime \prime}$ & 295 \\
\hline 6 & Araguatins & Araguatins & 548000 & $5^{\circ} 38^{\prime} 54^{\prime \prime}$ & $48^{\circ} 7^{\prime} 30^{\prime \prime}$ & 122 \\
\hline 7 & Arapoema & Arapoema & 749000 & $7^{\circ} 39^{\prime} 19^{\prime \prime}$ & $49^{\circ} 3^{\prime} 54^{\prime \prime}$ & 215 \\
\hline 8 & Aurora do Norte & Aurora do Norte & 1246001 & $12^{\circ} 42^{\prime} 50^{\prime \prime}$ & $46^{\circ} 24^{\prime} 31^{\prime \prime}$ & 464 \\
\hline 9 & Boa Vista do Araguaia & Araguaína & 749001 & $7^{\circ} 19^{\prime} 23^{\prime \prime}$ & $49^{\circ} 13^{\prime} 27^{\prime \prime}$ & 100 \\
\hline 10 & Campos Lindos & Campos Lindos & 847002 & $7^{\circ} 58^{\prime} 16^{\prime \prime}$ & $46^{\circ} 48^{\prime} 23^{\prime \prime}$ & 290 \\
\hline
\end{tabular}


Continuação ...

\begin{tabular}{|c|c|c|c|c|c|c|}
\hline 11 & Cangussu & Pium & 950002 & $9^{\circ} 58^{\prime} 13^{\prime \prime}$ & $49^{\circ} 59^{\prime} 37^{\prime \prime}$ & 240 \\
\hline 12 & Caseara & Caseara & 950000 & $9^{\circ} 16^{\prime} 12^{\prime \prime}$ & $49^{\circ} 57^{\prime} 32^{\prime \prime}$ & 190 \\
\hline 13 & Colinas do Tocantins & Colinas do Tocantins & 848000 & $8^{\circ} 3^{\prime} 10^{\prime \prime}$ & $48^{\circ} 28^{\prime} 54^{\prime \prime}$ & 229 \\
\hline 14 & Colônia & Bernardo Sayão & 748001 & $7^{\circ} 52^{\prime} 40^{\prime \prime}$ & $48^{\circ} 52^{\prime} 43^{\prime \prime}$ & 200 \\
\hline 15 & Conceição do Tocantins & Conceição do Tocantins & 1247000 & $12^{\circ} 13^{\prime} 57^{\prime \prime}$ & $47^{\circ} 19^{\prime} 28^{\prime \prime}$ & 407 \\
\hline 16 & Dianópolis & Dianópolis & 1146000 & $11^{\circ} 37^{\prime} 31^{\prime \prime}$ & $46^{\circ} 48^{\prime} 38^{\prime \prime}$ & 679 \\
\hline 17 & Dois Irmãos do Tocantins & Dois Irmãos do Tocantins & 949001 & $9^{\circ} 15^{\prime} 26^{\prime \prime}$ & $49^{\circ} 3^{\prime} 51^{\prime \prime}$ & 264 \\
\hline 18 & Duere & Dueré & 1149000 & $11^{\circ} 20^{\prime} 20^{\prime \prime}$ & $49^{\circ} 15^{\prime} 55^{\prime \prime}$ & 234 \\
\hline 19 & Fátima & Fátima & 1048000 & $10^{\circ} 45^{\prime} 49^{\prime \prime}$ & $48^{\circ} 54^{\prime} 8^{\prime \prime}$ & 352 \\
\hline 20 & Fazenda Lobeira & São Valério da Natividade & 1148000 & $11^{\circ} 31^{\prime} 53^{\prime \prime}$ & $48^{\circ} 17^{\prime} 41^{\prime \prime}$ & 243 \\
\hline 21 & Fazenda Primavera & Nova Olinda & 748002 & $7^{\circ} 33^{\prime} 38^{\prime \prime}$ & $48^{\circ} 25^{\prime} 22^{\prime \prime}$ & 257 \\
\hline 22 & Fazenda Santa Rita & Paranã & 1247005 & $12^{\circ} 35^{\prime} 6^{\prime \prime}$ & $47^{\circ} 29^{\prime} 12^{\prime \prime}$ & 340 \\
\hline 23 & Formoso do Araguaia & Formoso do Araguaia & 1149001 & $11^{\circ} 47^{\prime} 50^{\prime \prime}$ & $49^{\circ} 31^{\prime} 30^{\prime \prime}$ & 247 \\
\hline 24 & Goiatins & Goiatins & 747001 & $7^{\circ} 42^{\prime} 53^{\prime \prime}$ & $47^{\circ} 18^{\prime} 54^{\prime \prime}$ & 185 \\
\hline 25 & Guarai & Guaraí & 848001 & $8^{\circ} 49^{\prime} 55^{\prime \prime}$ & $48^{\circ} 49^{\prime} 2^{\prime \prime}$ & 279 \\
\hline 26 & Gurupi & Gurupi & 1149002 & $11^{\circ} 44^{\prime} 14^{\prime \prime}$ & $49^{\circ} 8^{\prime} 10^{\prime \prime}$ & 353 \\
\hline 27 & Itacajá & Itacajá & 847001 & $8^{\circ} 23^{\prime} 30^{\prime \prime}$ & $47^{\circ} 45^{\prime} 46^{\prime \prime}$ & 250 \\
\hline 28 & Itaporã do Tocantins & Itaporã do Tocantins & 848002 & $8^{\circ} 34^{\prime} 26^{\prime \prime}$ & $48^{\circ} 41^{\prime} 25^{\prime \prime}$ & 345 \\
\hline 29 & Jatobá (Fazenda Boa Nova) & Novo Acordo & 1047000 & $9^{\circ} 59^{\prime} 26^{\prime \prime}$ & $47^{\circ} 28^{\prime} 43^{\prime \prime}$ & 201 \\
\hline 30 & Lizarda & Lizarda & 946003 & $9^{\circ} 35^{\prime} 50^{\prime \prime}$ & $46^{\circ} 40^{\prime} 22^{\prime \prime}$ & 620 \\
\hline 31 & Mansinha & Rio Sono & 947001 & $9^{\circ} 27^{\prime} 27^{\prime \prime}$ & $47^{\circ} 19^{\prime} 37^{\prime \prime}$ & 320 \\
\hline 32 & Miracema do Tocantins & Miracema do Tocantins & 948000 & $9^{\circ} 33^{\prime} 51^{\prime \prime}$ & $48^{\circ} 23^{\prime} 15^{\prime \prime}$ & 210 \\
\hline 33 & Muricilândia & Muricilândia & 748003 & $7^{\circ} 9^{\prime} 16^{\prime \prime}$ & $48^{\circ} 36^{\prime} 11^{\prime \prime}$ & 393 \\
\hline 34 & Natividade & Natividade & 1147001 & $11^{\circ} 41^{\prime} 49^{\prime \prime}$ & $47^{\circ} 43^{\prime} 42^{\prime \prime}$ & 308 \\
\hline 35 & Palmas & Porto Nacional & 1048003 & $10^{\circ} 43^{\prime} 0^{\prime \prime}$ & $48^{\circ} 25^{\prime} 0^{\prime \prime}$ & 280 \\
\hline 36 & Palmeirante & Palmeirante & 747009 & $7^{\circ} 51 ' 34^{\prime \prime}$ & $47^{\circ} 55^{\prime} 44^{\prime \prime}$ & 166 \\
\hline 37 & Palmeirópolis & Palmeirópolis & 1248003 & $13^{\circ} 2^{\prime} 31^{\prime \prime}$ & $48^{\circ} 24^{\prime} 25^{\prime \prime}$ & 435 \\
\hline 38 & Paraíso do Tocantins & Paraíso do Tocantins & 1048001 & $10^{\circ} 9^{\prime} 55^{\prime \prime}$ & $48^{\circ} 53^{\prime} 26^{\prime \prime}$ & 390 \\
\hline 39 & Pindorama do Tocantins & Pindorama do Tocantins & 1147002 & $11^{\circ} 8^{\prime} 25^{\prime \prime}$ & $47^{\circ} 34^{\prime} 36^{\prime \prime}$ & 444 \\
\hline 40 & Piraquê & Araguanã & 648002 & $6^{\circ} 40^{\prime} 20^{\prime \prime}$ & $48^{\circ} 28^{\prime} 13^{\prime \prime}$ & 184 \\
\hline 41 & Pium & Pium & 1049001 & $10^{\circ} 26^{\prime} 28^{\prime \prime}$ & $49^{\circ} 10^{\prime} 45^{\prime \prime}$ & 280 \\
\hline 42 & Ponte Alta do Bom Jesus & Ponte Alta do Bom Jesus & 1246000 & $12^{\circ} 5^{\prime} 27^{\prime \prime}$ & $46^{\circ} 28^{\prime} 46^{\prime \prime}$ & 519 \\
\hline 43 & Ponte Alta do Tocantins & Ponte Alta do Tocantins & 1047004 & $10^{\circ} 45^{\prime \prime \prime}$ & $47^{\circ} 32^{\prime} 10^{\prime \prime}$ & 300 \\
\hline 44 & Porto Gilândia & Monte do Carmo & 1047002 & $10^{\circ} 45^{\prime} 19^{\prime \prime}$ & $47^{\circ} 45^{\prime} 53^{\prime \prime}$ & 220 \\
\hline 45 & Porto Lemos & Santa Fé do Araguaia & 649003 & $6^{\circ} 52^{\prime} 9^{\prime \prime}$ & $49^{\circ} 5^{\prime} 55^{\prime \prime}$ & 156 \\
\hline 46 & Porto Real & Pedro Afonso & 948001 & $9^{\circ} 18^{\prime} 25^{\prime \prime}$ & $47^{\circ} 55^{\prime} 45^{\prime \prime}$ & 200 \\
\hline 47 & Praia Alta & Sandolândia & 1249004 & $12^{\circ} 25^{\prime} 5^{\prime \prime}$ & $49^{\circ} 35^{\prime} 24^{\prime \prime}$ & 205 \\
\hline 48 & Projeto Rio Formoso & Formoso do Araguaia & 1249002 & $11^{\circ} 50^{\prime} 22^{\prime \prime}$ & $49^{\circ} 46^{\prime} 18^{\prime \prime}$ & 196 \\
\hline 49 & $\begin{array}{c}\text { Rio da Palma (Fazenda Chuva } \\
\text { Manga) }\end{array}$ & Conceição do Tocantins & 1247002 & $12^{\circ} 24^{\prime} 56^{\prime \prime}$ & $47^{\circ} 11^{\prime} 59^{\prime \prime}$ & 322 \\
\hline 50 & Santa Terezinha & Fortaleza do Tabocão & 1050002 & $10^{\circ} 27^{\prime} 40^{\prime \prime}$ & $50^{\circ} 30^{\prime} 45^{\prime \prime}$ & 207 \\
\hline 51 & São Sebastião do Tocantins & $\begin{array}{l}\text { São Sebastião do } \\
\text { Tocantins }\end{array}$ & 548001 & $5^{\circ} 15^{\prime} 35^{\prime \prime}$ & $48^{\circ} 12^{\prime} 25^{\prime \prime}$ & 109 \\
\hline
\end{tabular}

Continua... 


\begin{tabular}{|c|c|c|c|c|c|c|}
\hline \multicolumn{7}{|r|}{ tinuaçã } \\
\hline 52 & Taquarussu do Porto & Palmas & 1048005 & $10^{\circ} 18^{\prime} 48^{\prime \prime}$ & $48^{\circ} 9^{\prime} 45^{\prime \prime}$ & 406 \\
\hline 53 & Tocantinópolis & Tocantinópolis & 647000 & $6^{\circ} 17^{\prime} 19^{\prime \prime}$ & $47^{\circ} 23^{\prime} 31^{\prime \prime}$ & 126 \\
\hline 54 & Tupiratins & Tupiratins & 848003 & $8^{\circ} 23^{\prime} 57^{\prime \prime}$ & $48^{\circ} 7^{\prime} 49^{\prime \prime}$ & 192 \\
\hline 55 & Wanderlândia & Wanderlândia & 647001 & $6^{\circ} 50^{\prime} 21^{\prime \prime}$ & $47^{\circ} 58^{\prime} 14^{\prime \prime}$ & 165 \\
\hline 56 & Xambioá & Xambioá & 648000 & $6^{\circ} 24 ' 47^{\prime \prime}$ & $48^{\circ} 32^{\prime} 0^{\prime \prime}$ & 148 \\
\hline \multicolumn{7}{|c|}{ Postos Pluviométricos do entorno da área de estudo } \\
\hline \multicolumn{7}{|c|}{ Goiás (GO) } \\
\hline & Nome do Posto & Município & Código & $\begin{array}{l}\text { Latitude } \\
\text { (S) }\end{array}$ & $\begin{array}{l}\text { Longitude } \\
\text { (W) }\end{array}$ & $\begin{array}{l}\text { Altitude } \\
\text { (m) }\end{array}$ \\
\hline 1 & Entroncamento São Miguel & Porangatu & 1349003 & $13^{\circ} 6^{\prime} 10^{\prime \prime}$ & $49^{\circ} 12^{\prime} 5^{\prime \prime}$ & 345 \\
\hline 2 & Fazenda Piratininga & São Miguel do Araguaia & 1250000 & $12^{\circ} 49^{\prime} 14^{\prime \prime}$ & $50^{\circ} 20^{\prime} 10^{\prime \prime}$ & 254 \\
\hline 3 & Monte Alegre de Goiás & Monte Alegre de Goiás & 1346003 & $13^{\circ} 5^{\prime} 24^{\prime \prime}$ & $46^{\circ} 53^{\prime} 12^{\prime \prime}$ & 559 \\
\hline 4 & Novo Planalto & Novo Planalto & 1349001 & $13^{\circ} 14^{\prime} 41^{\prime \prime}$ & $49^{\circ} 30^{\prime} 6^{\prime \prime}$ & 286 \\
\hline 5 & Ponte Paranã & Teresina de Goiás & 1347001 & $13^{\circ} 25^{\prime} 31^{\prime \prime}$ & $47^{\circ} 8^{\prime} 21^{\prime \prime}$ & 363 \\
\hline 6 & SAMA & Minaçú & 1348001 & $13^{\circ} 31^{\prime} 59^{\prime \prime}$ & $48^{\circ} 13^{\prime} 37^{\prime \prime}$ & 375 \\
\hline 7 & Trombas & Trombas & 1348003 & $13^{\circ} 30^{\prime} 46^{\prime \prime}$ & $48^{\circ} 44^{\prime} 42^{\prime \prime}$ & 391 \\
\hline \multicolumn{7}{|c|}{ Mato Grosso (MT) } \\
\hline & Nome do Posto & Município & Código & $\begin{array}{l}\text { Latitude } \\
\text { (S) }\end{array}$ & $\begin{array}{l}\text { Longitude } \\
\text { (W) }\end{array}$ & $\begin{array}{c}\text { Altitude } \\
\text { (m) }\end{array}$ \\
\hline 8 & Luciara & Luciara & 1050000 & $11^{\circ} 13^{\prime} 9^{\prime \prime}$ & $50^{\circ} 40^{\prime} 7 "$ & 182 \\
\hline 9 & São Félix do Araguaia & São Félix do Araguaia & 1150001 & $11^{\circ} 37^{\prime} 11^{\prime \prime}$ & $50^{\circ} 39^{\prime} 45^{\prime \prime}$ & 195 \\
\hline 10 & Vila Rica & Vila Rica & 951000 & $10^{\circ} 1^{\prime} 8^{\prime \prime}$ & $51^{\circ} 7^{\prime} 22^{\prime \prime}$ & 222 \\
\hline \multicolumn{7}{|c|}{ Pará (PA) } \\
\hline & Nome do Posto & Município & Código & $\begin{array}{c}\text { Latitude } \\
\text { (S) }\end{array}$ & $\begin{array}{c}\text { Longitude } \\
\text { (W) }\end{array}$ & $\begin{array}{c}\text { Altitude } \\
(\mathbf{m})\end{array}$ \\
\hline 11 & Barreira do Campo & Santana do Araguaia & 950001 & $9^{\circ} 13 ' 39^{\prime \prime}$ & $50^{\circ} 12^{\prime} 39^{\prime \prime}$ & 195 \\
\hline 12 & Fazenda Santa Elisa & Sapucaia & 649001 & $6^{\circ} 47^{\prime} 41^{\prime \prime}$ & $49^{\circ} 32^{\prime} 55^{\prime \prime}$ & 193 \\
\hline 13 & KM 60 PA-150 & Marabá & 549007 & $5^{\circ} 48^{\prime} 11^{\prime \prime}$ & $49^{\circ} 11^{\prime} 00^{\prime \prime}$ & 131 \\
\hline 14 & Posto da Serra & Rio Maria & 750001 & $7^{\circ} 30^{\prime} 22^{\prime \prime}$ & $50^{\circ} 2^{\prime} 41^{\prime \prime}$ & 232 \\
\hline 15 & Redenção & Redenção & 855000 & $8^{\circ} 2^{\prime} 38^{\prime \prime}$ & $50^{\circ} 00^{\prime} 02^{\prime \prime}$ & 213 \\
\hline \multicolumn{7}{|c|}{ Maranhão (MA) } \\
\hline & Nome do Posto & Município & Código & $\begin{array}{l}\text { Latitude } \\
\text { (S) }\end{array}$ & $\begin{array}{l}\text { Longitude } \\
\text { (W) }\end{array}$ & $\begin{array}{c}\text { Altitude } \\
\text { (m) }\end{array}$ \\
\hline 16 & Brejo Comprido & Balsas & 746007 & $7^{\circ} 55^{\prime} 43^{\prime \prime}$ & $45^{\circ} 59^{\prime} 19^{\prime \prime}$ & 328 \\
\hline 17 & Cabeceira & Alto Parnaíba & 946000 & $9^{\circ} 18^{\prime} 00^{\prime \prime}$ & $46^{\circ} 42^{\prime} 00^{\prime \prime}$ & 600 \\
\hline 18 & Carolina & Carolina & 747000 & $7^{\circ} 19^{\prime} 23^{\prime \prime}$ & $47^{\circ} 27^{\prime} 52^{\prime \prime}$ & 169 \\
\hline 19 & Coqueiro & Riachão & 746002 & $7^{\circ} 40^{\prime} 00^{\prime \prime}$ & $46^{\circ} 28^{\prime} 00^{\prime \prime}$ & 320 \\
\hline 20 & Imperatriz & Imperatriz & 547000 & $5^{\circ} 32^{\prime} 06^{\prime \prime}$ & $47^{\circ} 28^{\prime} 42^{\prime \prime}$ & 124 \\
\hline 21 & Morrinhos & Alto Parnaíba & 946002 & $9^{\circ} 27^{\prime} 00^{\prime \prime}$ & $46^{\circ} 18^{\prime} 00^{\prime \prime}$ & 520 \\
\hline 22 & São Pedro & Porto Franco & 646003 & $6^{\circ} 38^{\prime} 00^{\prime \prime}$ & $46^{\circ} 53^{\prime} 00^{\prime \prime}$ & 450 \\
\hline \multicolumn{7}{|c|}{ Bahia (BA) } \\
\hline & Nome do Posto & Município & Código & $\begin{array}{c}\text { Latitude } \\
\text { (S) }\end{array}$ & $\begin{array}{l}\text { Longitude } \\
\text { (W) }\end{array}$ & $\begin{array}{c}\text { Altitude } \\
(\mathbf{m})\end{array}$ \\
\hline 23 & Cacimbinha & Formosa do Rio Preto & 1146005 & $11^{\circ} 09^{\prime} 07^{\prime \prime}$ & $46^{\circ} 03^{\prime} 39^{\prime \prime}$ & 634 \\
\hline 24 & Coaceral & Formosa do Rio Preto & 1045006 & $10^{\circ} 33^{\prime} 44^{\prime \prime}$ & $45^{\circ} 41^{\prime} 42^{\prime \prime}$ & 774 \\
\hline 25 & Fazenda Johá & Barreiras & 1245014 & $12^{\circ} 07^{\prime} 32^{\prime \prime}$ & $45^{\circ} 48^{\prime} 39^{\prime \prime}$ & 725 \\
\hline 26 & Fazenda Triunfo & Formosa do Rio Preto & 1145020 & $11^{\circ} 27^{\prime} 37^{\prime \prime}$ & $45^{\circ} 36^{\prime} 55^{\prime \prime}$ & 772 \\
\hline 27 & Roda Velha & São Desidério & 1245015 & $12^{\circ} 45^{\prime} 55^{\prime \prime}$ & $45^{\circ} 56^{\prime} 38^{\prime \prime}$ & 761 \\
\hline
\end{tabular}

Fonte: ANA (2017)

Elaboração: Autores (2019) 


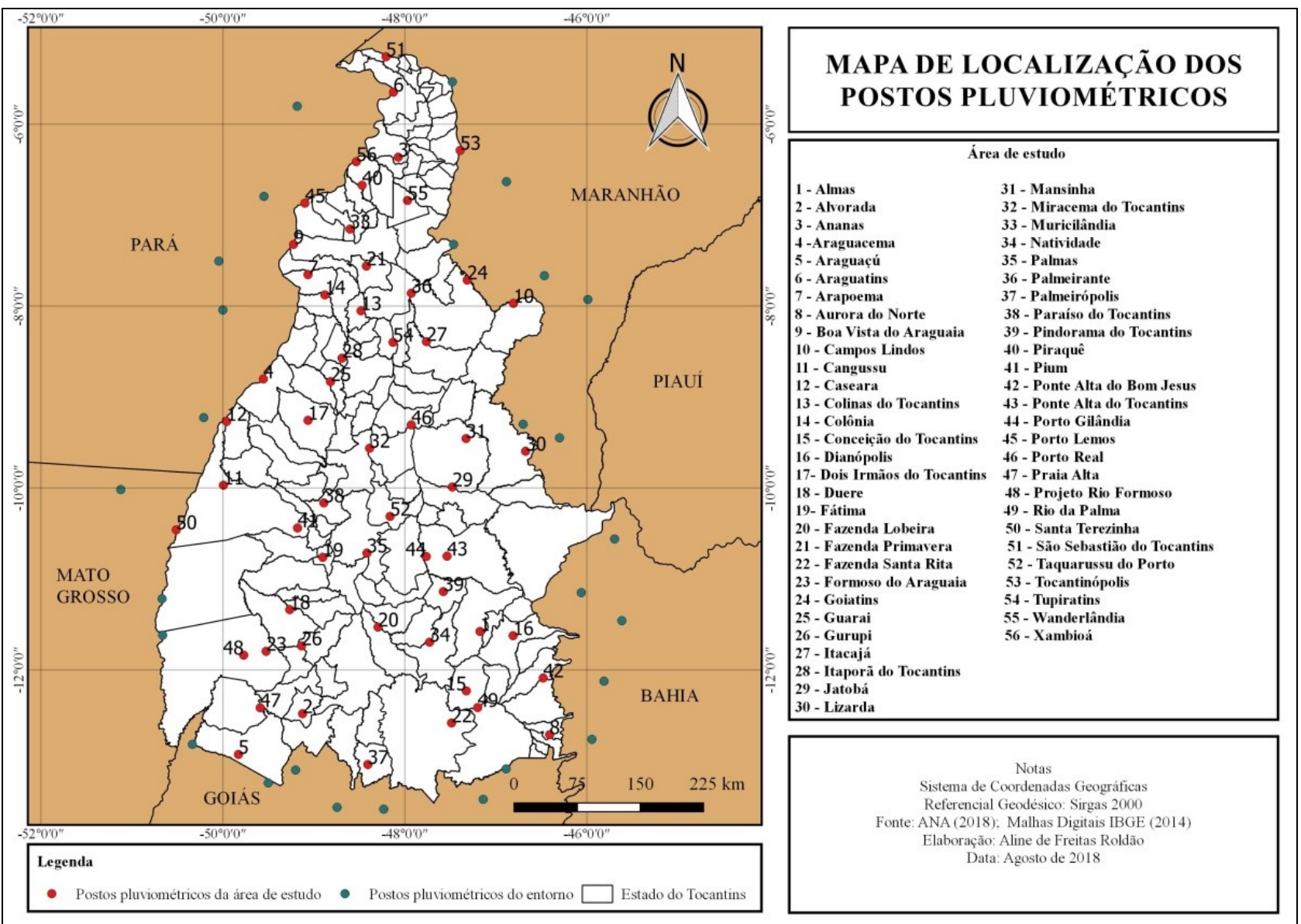

Figura 4 - Mapa de localização dos postos pluviométricos utilizados no estudo

Fonte: ANA (2018)

Após a seleção dos dados, foram realizados o tratamento e tabulação dos totais e das médias mensais. Para tal procedimento, foram utilizados os softwares Hidro 1.3 e Microsoft Office Excel. Para representar a distribuição espacial das precipitações no Estado foi utilizado o software QGIS, por meio do interpolador Multilevel b-spline interpolation.

Os dados de temperatura do ar foram obtidos a partir do projeto Reanalysis do National Centers for Environmental Prediction/National Center for Atmospheric Research (NCEP/NCAR).

O NCEP (National Centers for Environmental Predction) e NCAR (National Center for Atmospheric Research) estão cooperando num projeto (denominadas "Reanalysis") para produzir um registro de análises globais dos campos atmosféricos para apoio às necessidades de comunidades de pesquisa e monitoramento do clima. Esse esforço envolve a recuperação de dados de superfície terrestre, navio, radiossonda, aviões, satélites e outros dados, controle de qualidade e assimilar esses dados com um sistema de assimilação de dados. O NCEP / NCAR usa o estado da arte em sistemas de assimilação global de dados e uma base de dados tão completo quanto possível. A assimilação de dados e o modelo utilizado é idêntico ao do sistema global implementado operacionalmente no NCEP em 11 de janeiro de 1995, exceto que a resolução horizontal é T62 (cerca de $210 \mathrm{~km}$ ). A base de dados foi reforçada com várias fontes de observações que não estão disponíveis em tempo real das operações por diferentes países e organizações. O sistema foi concebido com controle de qualidade e componentes avançados de acompanhamento (KALNAY et al., 1996, p.437). 
O Reanálise engloba variáveis de dados climáticos com quatro valores diários e ainda valores mensais de 1948 até o presente. A área de cobertura abrange todo o globo, em 17 níveis de pressão, sendo que neste trabalho os dados foram coletados em um nível de pressão de 1000 mbar (nível de superfície). Os dados utilizados neste modelo são enfocados em uma grade de 144x73 pontos, com espaçamento horizontal de $2,5^{\circ}$ de latitude e $2,5^{\circ}$ de longitude.

Para o Estado do Tocantins foram utilizados os dados de temperatura compreendidos entre as latitudes de $5^{\circ}$ a $12,5^{\circ}$ sul e entre as longitudes de $45^{\circ}$ a $50^{\circ}$ oeste. A fim de especializar a temperatura no Estado foi elaborado um mapa base utilizando a mesma inserção de pontos (localização) dos postos pluviométricos. Para tal também foi utilizado o software QGIS. Em seguida, com o mesmo software, foi feita a interpolação, através do interpolador Multilevel b-spline interpolation e finalmente a elaboração do mapa de temperatura média anual do Estado do Tocantins.

O cálculo do balanço hídrico foi feito a partir da metodologia proposta por Thornthwaite e Mather (1955), com a Capacidade de água disponível no solo (CAD) de $100 \mathrm{~mm}$ como valor padrão. Os solos predominantes no território apresentam valores próximos disso. No intuito de facilitar o cálculo utilizou-se a planilha elaborada por Rollin e Sentelhas (1999). A figura 5 mostra como exemplo o balanço hídrico elaborado por meio de dados do posto pluviométrico no município de Palmas, para o período compreendido entre 1985 e 2016.

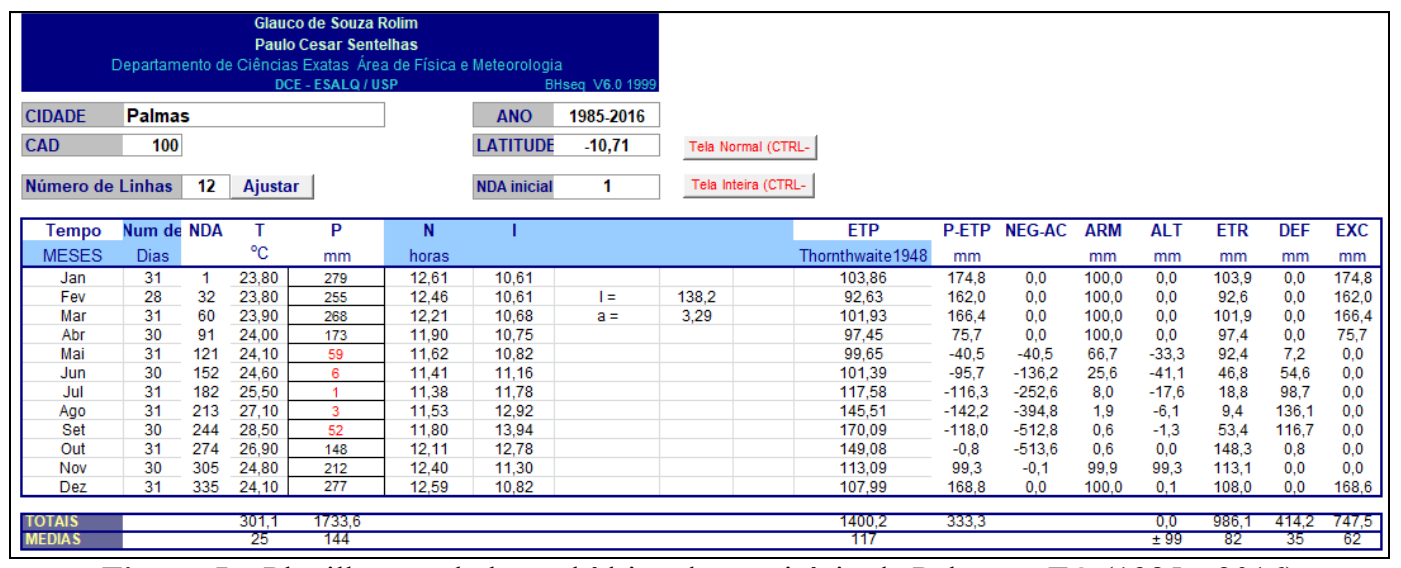

Figura 5 - Planilha com balanço hídrico do município de Palmas - TO (1985 a 2016)

Elaboração: Rollin e Sentelhas (1999)

Organização: Autores (2018)

Foram calculados os balanços hídricos segundo Thornthwaite e Mather (1955) para os 56 postos pluviométricos localizados no Estado do Tocantins e também para os 27 postos selecionados no entorno. A partir do cálculo do balanço hídrico foram gerados os valores da deficiência hídrica e do excedente hídrico. No cômputo do balanço hídrico, a deficiência de água ocorre sempre que a umidade do solo esta esgotada ao ponto de murcha permanente. Em contrapartida, o excedente ocorre quando a chuva excede a capacidade de armazenagem de umidade no solo. O escoamento da DOI 10.5752/p.2318-2962.2019v29n59p1161 
superfície e a percolação profunda são agrupados ao excedente (MOTA, 1985). Foram elaborados mapas do excedente e déficit anual. Os mesmos também foram feitos utilizando o software QGIS e a interpolação através do interpolador Multilevel b-spline interpolation.

Os climas do Tocantins foram classificados de acordo com as propostas de Köppen \& Geiger e Thornthwaite. A primeira é descritiva e baseada em intervalos de dados de pluviosidade e temperatura. A segunda é baseada no balanço hídrico climatológico.

\section{RESULTADOS E DISCUSSÕES}

\subsection{Temperatura do ar}

O Estado do Tocantins possui uma média geral de temperatura do ar de $24,9^{\circ} \mathrm{C}$. Os meses mais quentes são agosto, setembro e outubro, com valores médios respectivos de $26,6^{\circ} \mathrm{C} ; 27,7^{\circ} \mathrm{C}$ e $26,4^{\circ} \mathrm{C}$. Já os meses com temperaturas menores são: janeiro $\left(23,9^{\circ} \mathrm{C}\right)$, fevereiro $\left(23,9^{\circ} \mathrm{C}\right)$ e março $\left(24^{\circ} \mathrm{C}\right)$. Os municípios que apresentam menores médias de temperatura são Aurora do Norte e Conceição do Tocantins, ambos com média de $23,2^{\circ} \mathrm{C}$. Em contrapartida, o município com maior média de temperatura é Tocantinópolis $\left(26^{\circ} \mathrm{C}\right)$. A figura 6 representa as variações espaciais da temperatura média anual no Estado do Tocantins no período de 1985 a 2016. Observa-se que o Estado possui uma pequena variação de temperatura. Fica evidenciado que a temperatura média no Estado aumenta no sentido sul-norte.

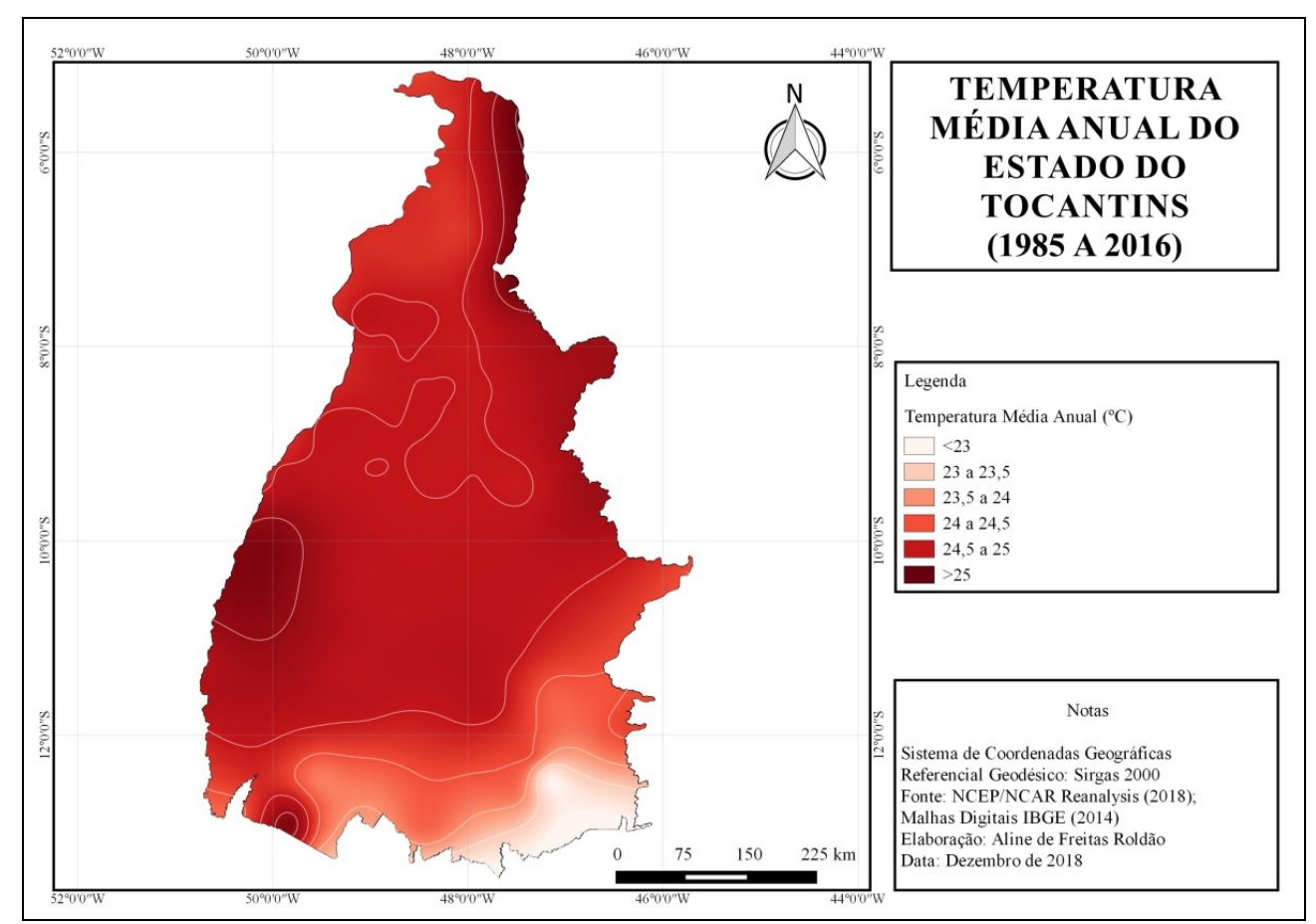

Figura 6 - Mapa da temperatura média anual do Tocantins (1985 a 2016).

Dados: NCEP/NCAR Reanalysis (2018)

Organização: Autores (2018) 


\subsection{Pluviosidade}

Diferentemente das temperaturas médias, a distribuição dos totais médios anuais e mensais de pluviosidade não é uniforme no espaço e no tempo. A média de total pluviométrico anual no Estado é de 1642,9 mm. Existe no Estado do Tocantins uma alternância entre seis meses de chuva e seis meses de seca (figura 7). As chuvas concentram-se nos meses de novembro a abril, somando $1404 \mathrm{~mm}$ em média, o equivalente a $85 \%$ das chuvas anuais. O mês de janeiro evidencia-se com a maior média pluviométrica do Estado (265,0 mm).

Entre maio e outubro predomina escassez de chuvas. Neste período a média precipitada é de $243,9 \mathrm{~mm}$, o que corresponde a apenas $15 \%$ do total das chuvas anuais. Julho é o mês com menor registro pluviométrico, com média de 3,8 mm. O mês de outubro, apesar de receber uma quantidade considerável de chuvas, apresenta ainda deficiência hídrica no solo e as chuvas são em grande parte isoladas. Desta forma outubro ainda é considerado um mês da estação seca no Tocantins.

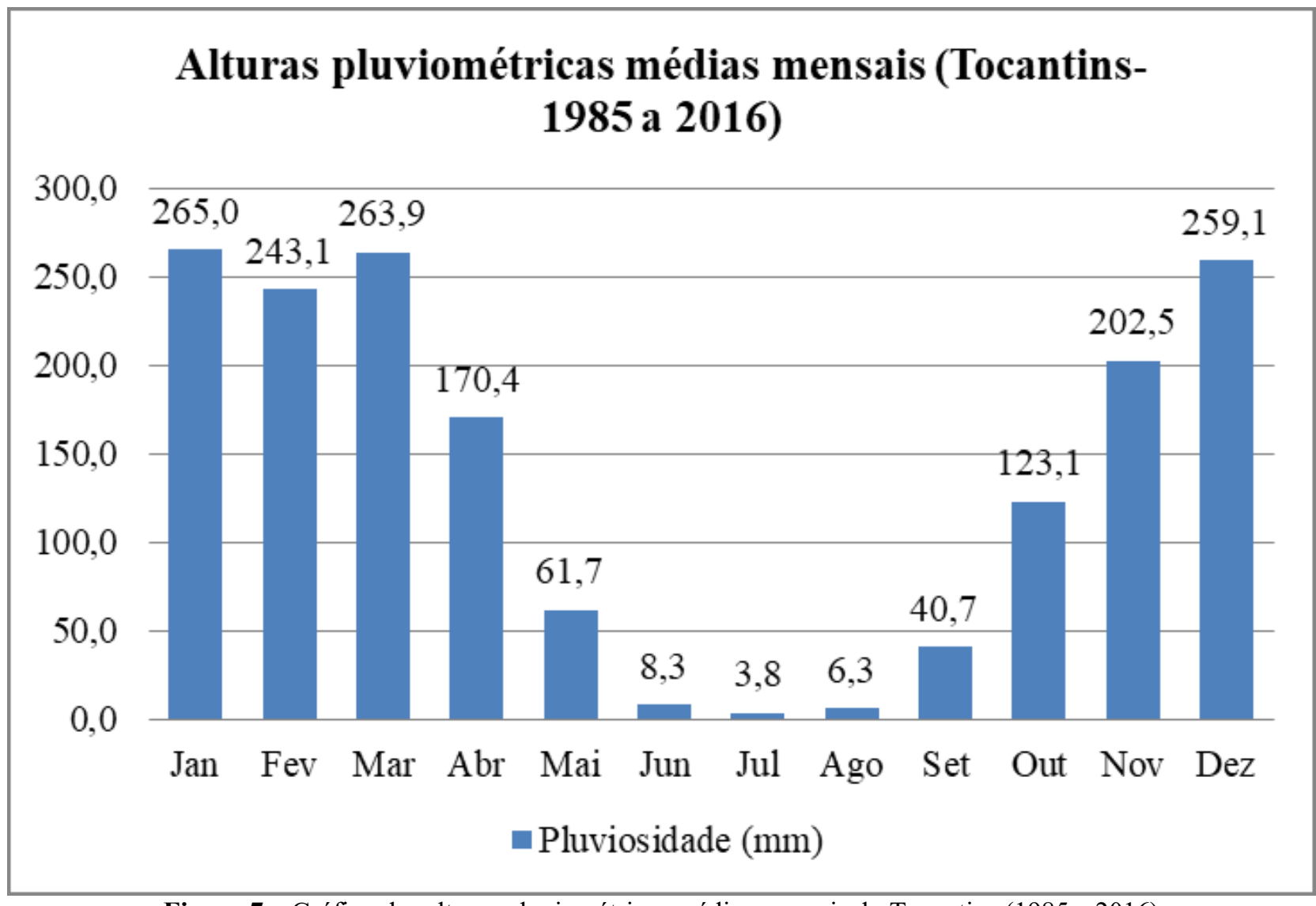

Figura 7 - Gráfico das alturas pluviométricas médias mensais do Tocantins (1985 a 2016)

Dados: ANA (2018)

Elaboração: Autores (2018) 
A figura 8 apresenta a espacialização dos totais médios anuais de pluviosidade no Estado do Tocantins no período de 1985 a 2016. A porção sul registra os menores totais, como é o caso do posto pluviométrico Fazenda Santa Rita no município de Paranã com registro de apenas $1090 \mathrm{~mm}$ de total médio.

À medida que se orienta para a direção norte-noroeste, observa-se um aumento gradativo da precipitação. Nestas áreas estão localizados os postos pluviométricos com médias maiores que 1900 mm, como Paraíso do Tocantins com um acumulado médio de 1986,6 mm, Dois Irmãos do Tocantins com 1985,1 mm, Muricilândia com 1957 mm, Pium com 1955,4 mm, Fátima com 1949,4 mm e Araguacema com 1925,2 mm. A maior média anual pluviométrica do Estado é registrada no posto situado no município de Ponte Alta do Bom Jesus, como pode ser notado na porção sudeste do território tocantinense, apresentando um total médio de 1992,7 mm.

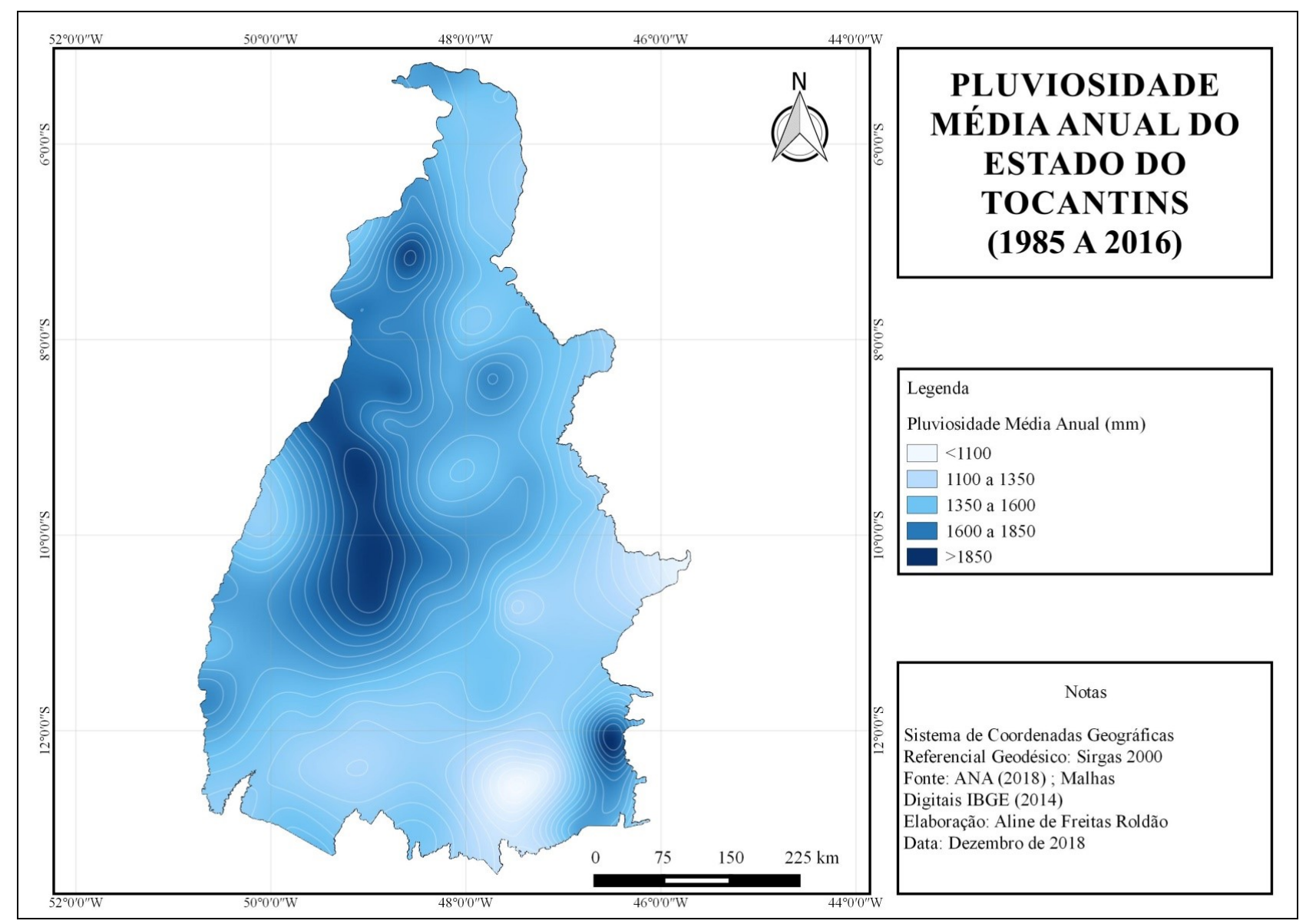

Figura 8 - Mapa da pluviosidade média anual do Estado do Tocantins (1985 a 2016)

Dados: ANA (2018)

Elaboração: Autores (2018)

Analisando concomitantemente o comportamento da temperatura e do regime pluviométrico constata-se, portanto, alternância de duas estações distintas, sendo uma com verão quente e úmido e outra com inverno também quente e seco. Fato importante de ser destacado são as temperaturas registradas durante o inverno no Tocantins, uma vez que as mesmas apresentam-se sempre com 
médias superior a $23^{\circ} \mathrm{C}$. Tal fato pode ser explicado pela pequena influência que as massas polares exercem sobre o território, além da redução de cobertura de nuvens que permite elevado número de horas de insolação efetiva.

As variações termo-pluviométricas são notadamente percebidas a partir do climograma da Figura 9. No verão registram-se os maiores totais pluviométricos, quando as chuvas atingem acumulados médios superiores a $250 \mathrm{~mm}$ mensais. Já as maiores médias de temperatura são registradas na primavera, sendo o mês de setembro o mais quente, com média de $27,7^{\circ} \mathrm{C}$.

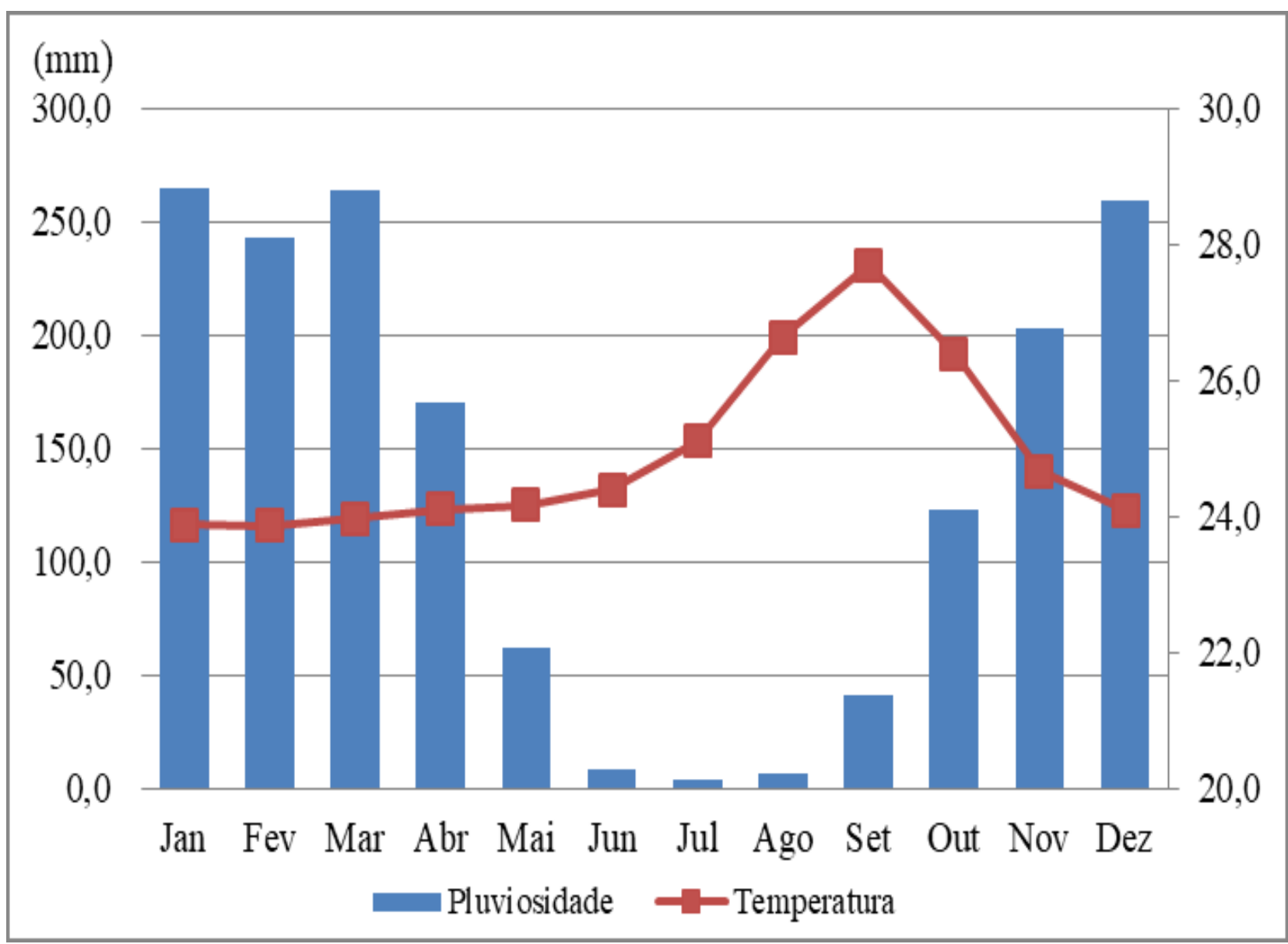

Figura 9 - Climograma do Estado do Tocantins (1985 a 2016) Dados: ANA (2018); NCEP/NCAR Reanalysis (2018)

Elaboração: Autores (2018)

\subsection{Excedente e deficiência hídrica anual}

A média do excedente hídrico do Estado é de $687,5 \mathrm{~mm}$. Os maiores valores ocorrem nos meses de janeiro $(158,5 \mathrm{~mm})$, fevereiro $(149,2 \mathrm{~mm})$ e março $(160,2 \mathrm{~mm})$. De maio a outubro prevalece deficiência. A partir da figura 10 é possível observar o comportamento do balanço hídrico no Estado no período analisado (1985-2016). 


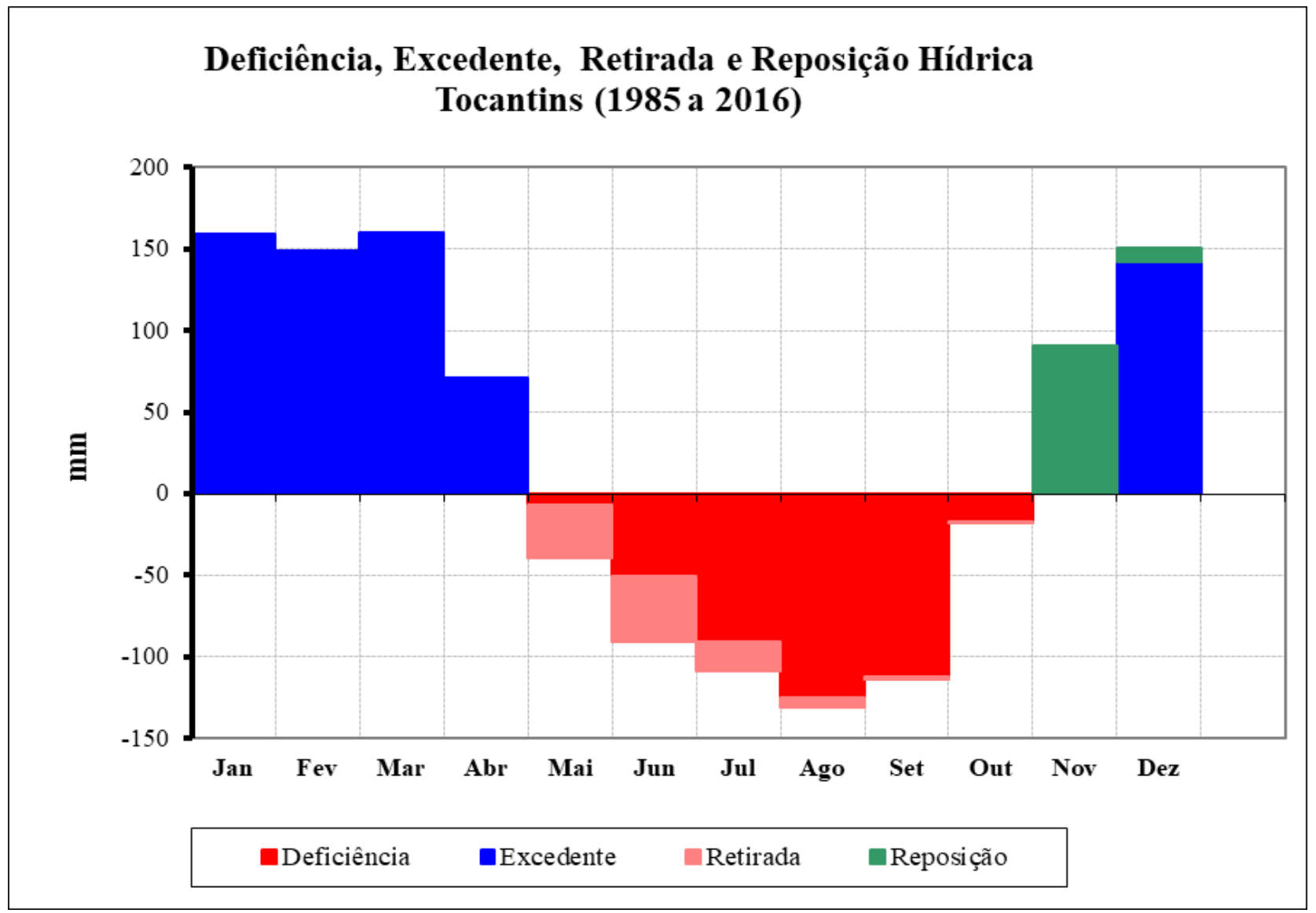

Figura 10 - Balanço Hídrico no Estado do Tocantins (1985-2016)

Dados: ANA (2018)

Elaboração: Autores (2018)

O posto pluviométrico do município de Ponte Alta do Bom Jesus possui o maior valor médio de excedente hídrico do Estado, sendo de 1098,8 mm. Em contrapartida o menor valor registrado ocorre no posto Fazenda Santa Rita, município de Paranã, com 313,3 mm de média.

Na figura 11, os dados dos excedentes hídricos estão espacializados. O excedente hídrico no Estado aumenta no sentido sudeste-noroeste. Na porção sudeste verifica-se uma faixa de cor mais clara que ocupa os valores médios menores que $500 \mathrm{~mm}$, como é o caso do posto fazenda Santa Rita, no município de Paranã, que possui o menor índice anual do Estado, com média de 313, $1 \mathrm{~mm}$ e outros postos como Rio da Palma (média de $418 \mathrm{~mm}$ ) e o posto Conceição do Tocantins (média de $463,2 \mathrm{~mm})$.

Os maiores valores estão dispostos na porção centro-oeste do Estado, com médias que ultrapassam $900 \mathrm{~mm}$, como é o caso dos seguintes postos: Dois Irmãos do Tocantins (998,7 mm); Fátima (998) e Pium (977,9 mm). É importante destacar o posto pluviométrico do município de Ponte Alta do Bom Jesus que registra o maior excedente hídrico do Estado (média anual de 1098,8 mm). Este posto apresenta também o maior índice pluviométrico do Tocantins que é de 1992,7 mm. 


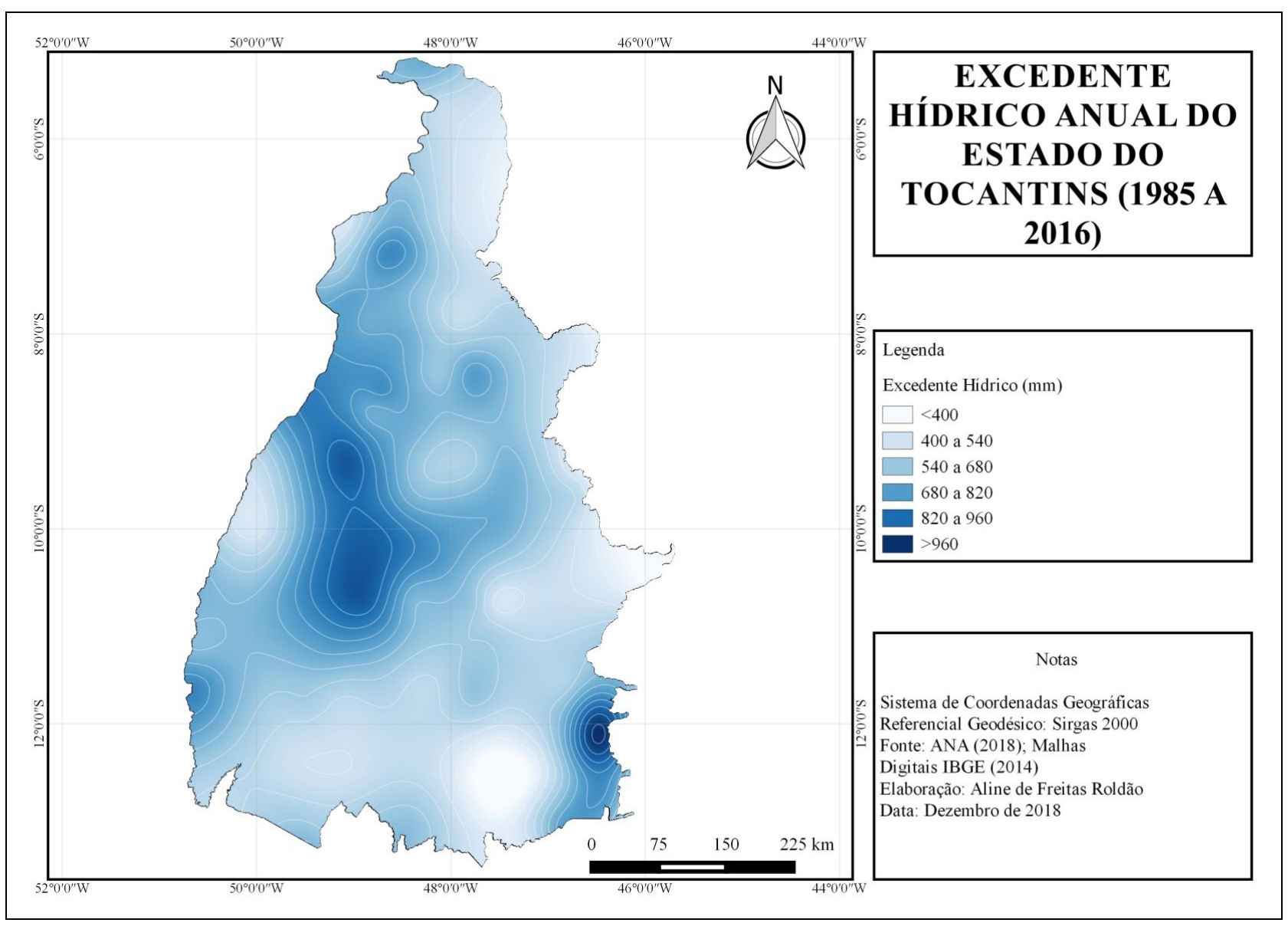

Figura 11 - Mapa do excedente hídrico anual do Estado do Tocantins (1985 a 2016)

Dados: ANA (2018)

Elaboração: Autores (2018)

A média da deficiência hídrica do Estado é de 414,3 mm. Os maiores valores ocorrem nos meses de julho $(92,1 \mathrm{~mm})$, agosto $(126,8 \mathrm{~mm})$ e setembro $(113,3 \mathrm{~mm})$. De outubro a maio são registrados os menores índices, sendo que de novembro a março os valores médios de deficiência são nulos, prevalecendo excedentes. O posto pluviométrico do município de Araguaçú registra o maior valor médio de deficiência hídrica, sendo de 544,1 mm. Já o menor valor de deficiência hídrica média anual é registrado no posto do município de Muricilândia, com 251,6 mm.

$\mathrm{Na}$ figura 12, os valores médios das deficiências hídricas estão espacializados. Fica claro que os valores aumentam no sentido norte-sul. A parte norte do Tocantins é destacada com uma faixa de cor mais clara que ocupa valores médios menores que $300 \mathrm{~mm}$, como é o caso do posto pluviométrico do município de Muricilândia, que possui o menor índice de deficiência anual do Estado, com 251,6 mm de média. Outros postos como Xambioá (média de 278,4 mm), Piraquê $(279,7 \mathrm{~mm})$ e Porto Lemos (297,7 mm) também apresentam baixa deficiência.

Os maiores valores estão dispostos na porção centro-sul do Estado, com médias que ultrapassam $500 \mathrm{~mm}$, como é o caso dos postos Cangussu com 511,8 mm e Ponte Alta do Tocantins 
com 524,4 mm. É importante destacar o posto pluviométrico do município de Araguaçú que registra o maior valor médio anual de deficiência hídrica do Estado $(544,1 \mathrm{~mm})$.

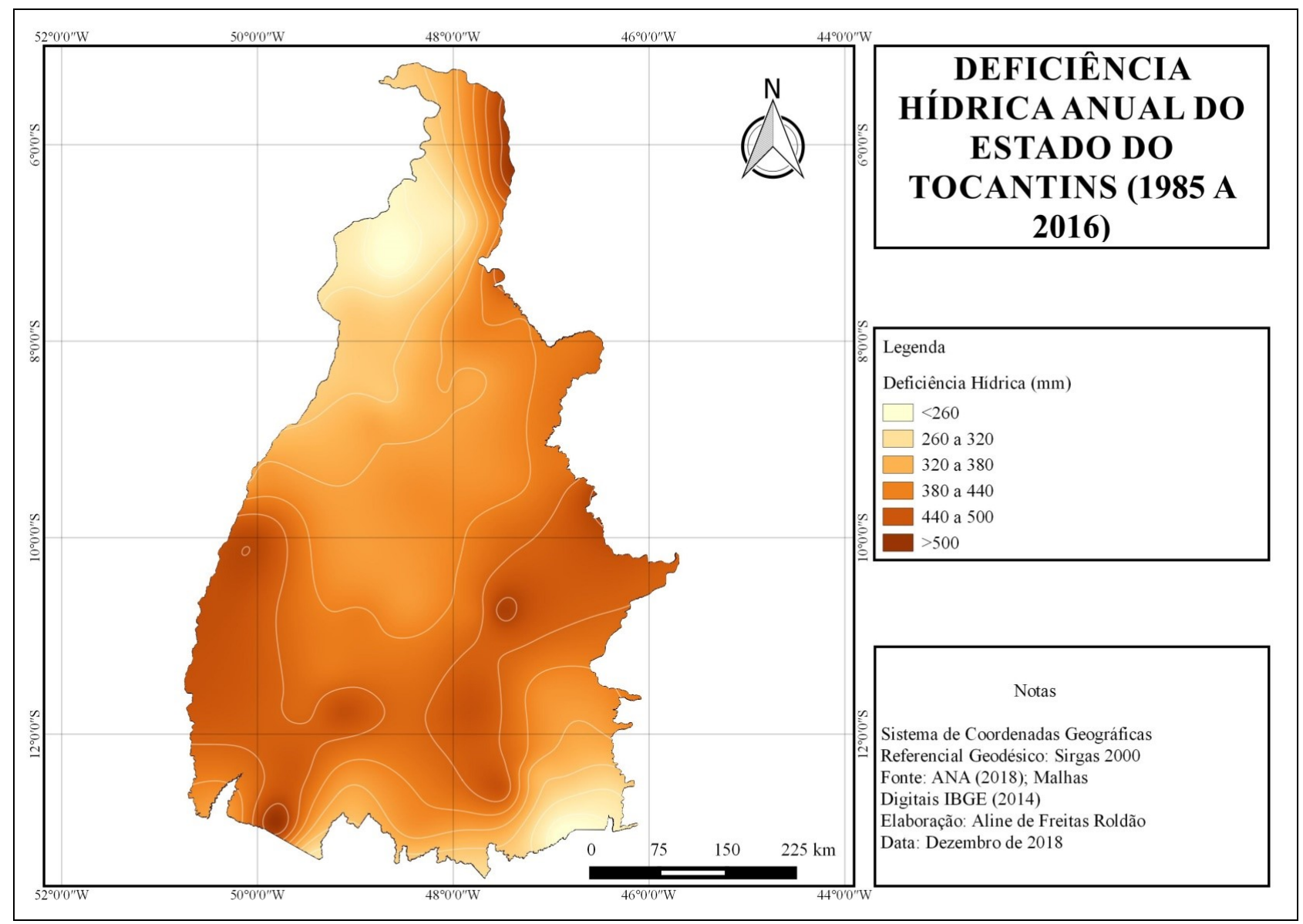

Figura 12 - Mapa da deficiência hídrica anual do Estado do Tocantins (1985 a 2016)

Dados: ANA (2018)

Elaboração: Autores (2018)

\subsection{Classificação climática}

\subsubsection{Köppen}

O clima do Tocantins é do tipo Aw (clima de savana), uma vez que o Tocantins apresenta temperatura média do mês mais frio acima de $18^{\circ} \mathrm{C}$ e ainda chuvas de verão. É possível observar, a partir da tabela 1, que as menores temperaturas ocorrem nos meses de janeiro e fevereiro, ambos com $23,9^{\circ} \mathrm{C}$ de média.

Tabela 1 - Temperaturas médias mensais e anuais do Estado do Tocantins (1985 a 2016)

\begin{tabular}{cccccccccccccc} 
Tocantins & Jan & Fev & Mar & Abr & Mai & Jun & Jul & Ago & Set & Out & Nov & Dez & Média \\
\hline Média de temperatura & 23,9 & 23,9 & 24,0 & 24,1 & 24,2 & 24,4 & 25,1 & 26,6 & 27,7 & 26,4 & 24,7 & 24,1 & 24,9 \\
\hline \multicolumn{1}{c}{ Dados: NCEP/NCAR Reanalysis (2018) } \\
Organização: Autores (2018)
\end{tabular}


Já a tabela 2 apresenta as médias dos totais pluviométricos do Estado do Tocantins no período de 1985 a 2016. Nota-se que os maiores valores ocorrem entre os meses de novembro e abril, especialmente nos meses centrais do verão.

Tabela 2 - Médias dos totais pluviométricos mensais e anuais do Estado do Tocantins (1985 a 2016)

\begin{tabular}{cccccccccccccc}
\hline Tocantins & Jan & Fev & Mar & Abr & Mai & Jun & Jul & Ago & Set & Out & Nov & Dez & Média \\
\hline Média pluviométrica & 265,0 & 243,1 & 263,9 & 170,4 & 61,7 & 8,3 & 3,8 & 6,3 & 40,7 & 123,1 & 202,5 & 259,1 & 1642,9 \\
\hline \multicolumn{1}{c}{ Dados: ANA $(2018)$} \\
& \multicolumn{1}{c}{ Organização: Autores $(2018)$} & & & & & &
\end{tabular}

Ayoade (2010) expressa que, apesar dessa classificação possuir uma abordagem quantitativa e objetiva, sempre recebeu muitas críticas, principalmente pelo fato da ausência de uma categoria subúmida. O principal crítico dessa classificação é autor de uma importante classificação climática aplicada no mundo (Charles Warren Thornthwaite). Este propôs uma classificação climática racional baseada no conceito de evapotranspiração potencial, no balanço hídrico e em um índice de umidade.

\subsubsection{Thorthwaite}

A tabela 3 apresenta a classificação segundo Thornthwaite (1948) e os valores das classes de Iu (Índice de umidade) de cada tipo climático. Foram classificados os tipos climáticos das 56 localidades utilizadas neste estudo. Percebe-se que, dentre os postos pluviométricos estudados, 34 deles, o que corresponde a aproximadamente $61 \%$, possuem o tipo climático Úmido - $\mathrm{B}_{1}$, ou seja, este clima predomina no Estado do Tocantins. O tipo climático Úmido $\left(\mathrm{B}_{2}\right)$ ocorre em 12 postos. Outros 9 postos apresentam o clima do tipo Sub-Úmido $\left(\mathrm{C}_{2}\right)$ e apenas um posto o tipo climático Úmido $\left(\mathrm{B}_{3}\right)$. Vale ressaltar o caso do clima Úmido $\left(\mathrm{B}_{3}\right)$, o qual ocorre no posto do município de Ponte Alta do Bom Jesus, sendo esta a localidade entre as demais que apresenta o maior acumulado pluviométrico do Tocantins $(1992,7 \mathrm{~mm})$, apresentando também o maior excedente hídrico do Estado.

Tabela 3 - Tipos climáticos no Estado do Tocantins

\begin{tabular}{cccc}
\hline Posto Pluviométrico & Iu & Tipo Climático & Símbolo \\
\hline Almas & 28,30 & Úmido & $\mathrm{B}_{1}$ \\
Alvorada & 22,96 & Úmido & $\mathrm{B}_{1}$ \\
Ananas & 27,52 & Úmido & $\mathrm{B}_{1}$ \\
Araguacema (Chácara Araguaia) & 49,58 & Úmido & $\mathrm{B}_{2}$ \\
Araguaçú & 20,94 & Úmido & $\mathrm{B}_{1}$ \\
Araguatins & 26,78 & Úmido & $\mathrm{B}_{1}$ \\
Arapoema & 42,95 & Úmido & $\mathrm{B}_{2}$ \\
\hline & & & Continua...
\end{tabular}




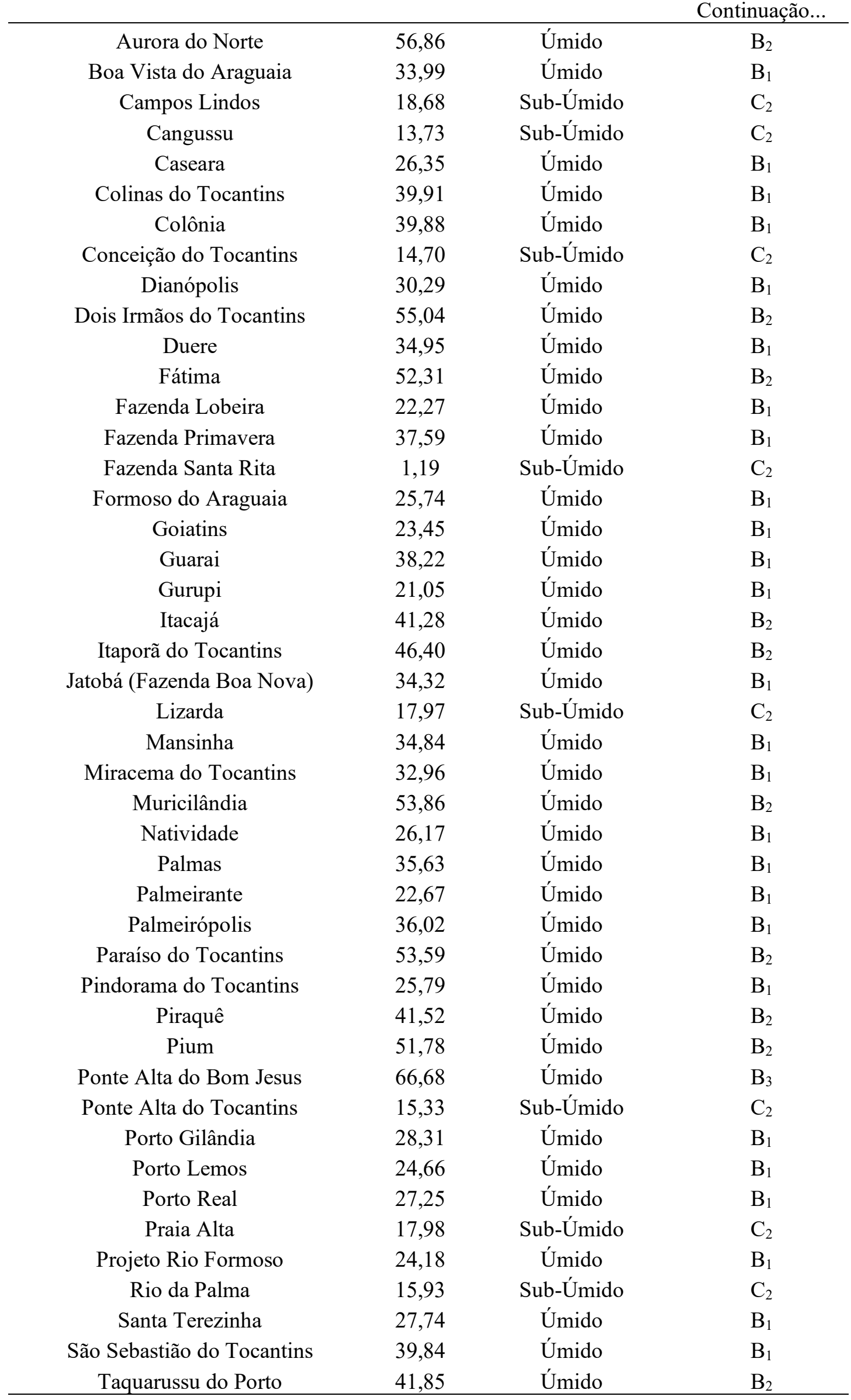

Continua... 


\begin{tabular}{cccc} 
& & & Continuação... \\
\hline Tocantinópolis & 6,70 & Sub-Úmido & $\mathrm{C}_{2}$ \\
Tupiratins & 31,75 & Úmido & $\mathrm{B}_{1}$ \\
Wanderlândia & 27,09 & Úmido & $\mathrm{B}_{1}$ \\
Xambioá & 38,33 & Úmido & $\mathrm{B}_{1}$ \\
\hline
\end{tabular}

Dados: ANA (2018)

Elaboração: Autores (2018)

A figura 13 mostra a distribuição dos tipos climáticos segundo Thornthwaite (1948) no território tocantinense. O tipo climático mais expressivo no Estado é o Úmido ( $\mathrm{B}_{1}$ ), o qual ocupa de norte a sul e de leste a oeste o Estado, como por exemplo, o município de Wanderlândia ao norte e o município de Palmeirópolis ao sul e ainda o município de Caseara a leste e Rio Sono a oeste.

O segundo tipo climático com maior predominância é o Úmido $\left(\mathrm{B}_{2}\right)$, o qual possui uma mancha espacializada na parte central do Estado, que vai em direção às porções oeste e norte, abrigando municípios como Paraíso do Tocantins, Dois Irmãos do Tocantins, Itaporã do Tocantins, Arapoema. Vale ressaltar a ocorrência deste tipo climático em uma pequena porção do sudeste do Estado.

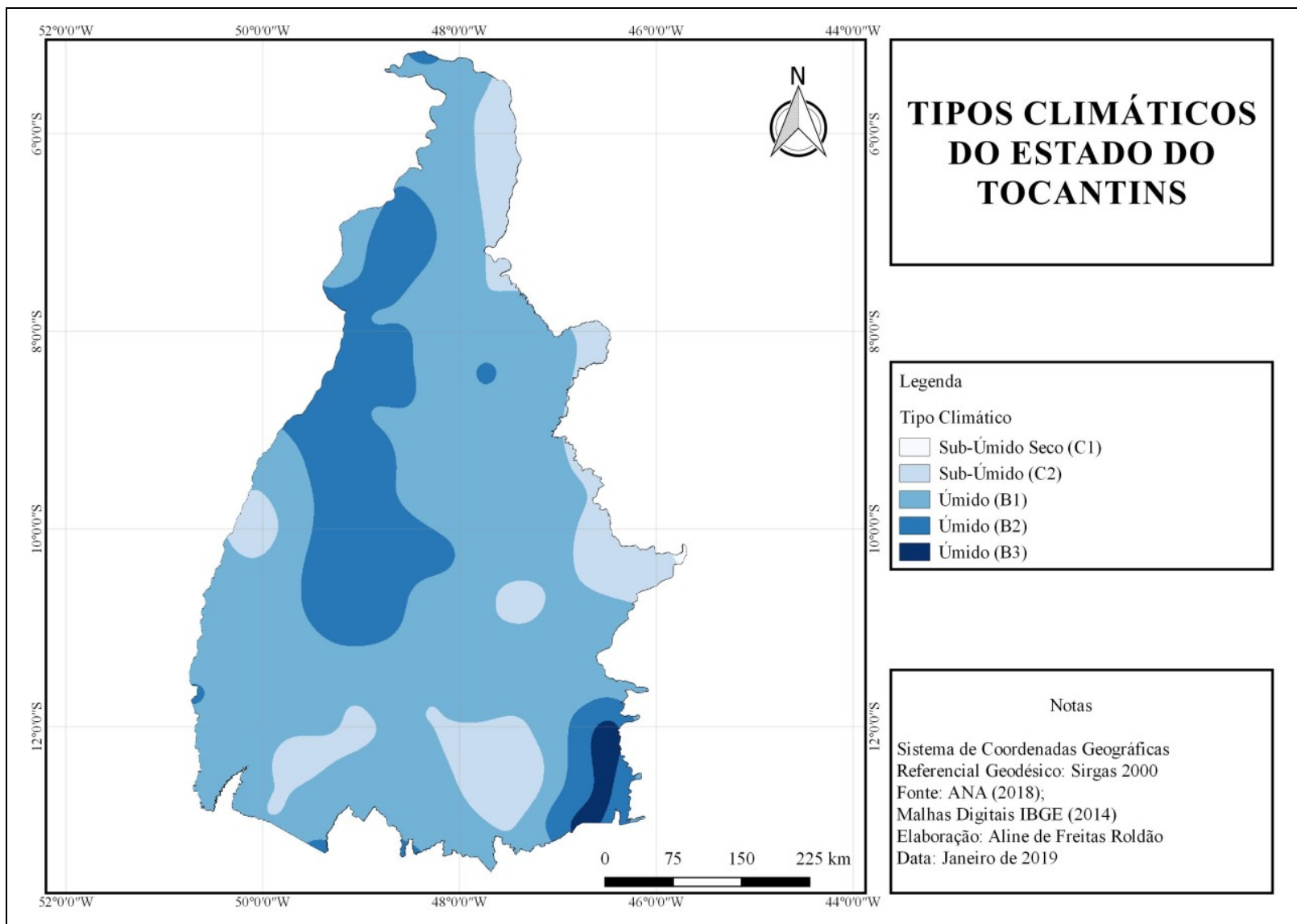

Figura 13 - Mapa dos tipos climáticos do Estado do Tocantins

Dados: ANA (2018)

Elaboração: Autores (2018) 
Em relação ao tipo climático Sub-Úmido $\left(\mathrm{C}_{2}\right)$, este ocupa uma menor porção do Estado, tomando parte dos municípios de Paranã, Ponte Alta do Tocantins, Mateiros, Campos Lindos, etc. Em alguns municípios, como é o caso de Tocantinópolis, o clima Sub-Úmido $\left(C_{2}\right)$ prevalece. No caso do clima Úmido $\left(\mathrm{B}_{3}\right)$, aparece apenas no posto pluviométrico do município de Ponte Alta do Bom Jesus, em virtude de ser o município analisado com maior concentração pluviométrica e consequentemente maior excedência hídrica do Estado, conforme já mencionado. $\mathrm{O}$ tipo $\mathrm{C}_{1}$ não aparece em nenhum posto, embora esteja presente no mapa por causa da interpolação com postos situados no entorno do Estado.

\section{CONCLUSÕES}

Foi apresentada uma atualização acerca das características climáticas do Estado do Tocantins no âmbito de uma escala climática regional, porém mencionando casos elucidativos em escala local. Observa-se que o Estado apresenta importantes especificidades climáticas internas, resultantes da dinâmica de atuação de sistemas da circulação atmosférica e também de determinações impostas por fatores estáticos.

O território estadual apresenta pequena variação de temperatura. A temperatura média aumenta no sentido sul-norte acompanhando a transição imposta pelo ciclo sazonal do ângulo de incidência solar e fotoperíodo. A porção sul registra os menores totais pluviométricos, que aumentam gradativamente na direção norte-noroeste. $\mathrm{O}$ excedente hídrico aumenta no sentido sudeste-noroeste. Na porção sudeste verifica-se valores médios menores que $500 \mathrm{~mm}$. Já os maiores valores de deficiência aparecem no centro-sul do Estado, com médias que ultrapassam $500 \mathrm{~mm}$ de deficiência.

Segundo a classificação de Köppen o clima do Tocantins é do tipo Aw (clima de savana), uma vez que apresenta temperatura média do mês mais frio acima de $18^{\circ} \mathrm{C}$ e ainda chuvas concentradas no verão. Aplicando-se a classificação de Thorthwaite percebe-se que, dentre os postos pluviométricos estudados, 34 deles $(61 \%)$ possuem o tipo climático Úmido $\left(\mathrm{B}_{1)}\right.$. O tipo climático Úmido $\left(\mathrm{B}_{2}\right)$ ocorre em 12 postos. Outros 9 postos apresentam o clima do tipo Sub-Úmido $\left(\mathrm{C}_{2}\right)$ e apenas um posto o tipo climático Úmido $\left(\mathrm{B}_{3}\right)$.

Permanece a necessidade de avaliação de aspectos relacionados aos eventos extremos de precipitações, com destaque para a frequência e intensidade de ocorrência de veranicos, que podem impactar significativamente atividades produtivas e aspectos relacionados à gestão territorial no Estado do Tocantins. 


\section{REFERÊNCIAS}

AGÊNCIA NACIONAL DE ÁGUAS - ANA (2014). Hidroweb - Sistema de Informações

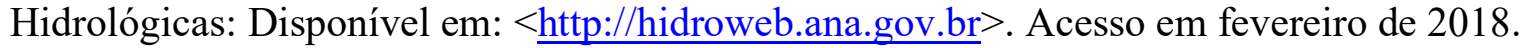

AYOADE, J.O. Introdução a Climatologia para os trópicos. Tradução de Maria Juraci Zani dos Santos, revisão de Suely Bastos; coordenação editorial de Antonio Christofoletti. 14a Edição: Rio de Janeiro, 2010.

CARVAlHO, L.M.V; JONES,C. Zona de Convergência do Atlântico Sul. In: Tempo e Clima no Brasil. Org. CAVALCANTI,I.F.A et.al. São Paulo: Oficina de textos, 2009.

HASTENRATH,S.; HELLER,L. Dynamics of climatic hazards in Northesat Brazil. Quarterly Journal of the Royal Meteorological Society, v.103, n. 435, p. 77-92, 1977.

INSTITUTO BRASILEIRO DE GEOGRAFIA E ESTATÍSTICA - IBGE. Malhas digitais Mapas. Disponível em: < http://mapas.ibge.gov.br/bases-e-referenciais/bases cartográficas/malhasdigitais $>$. Acesso em agosto de 2014.

INSTITUTO NACIONAL DE METEOROLOGIA - INMET (2019). Normais Climatológicas. Disponível em: $\quad<$ http://www.inmet.gov.br/portal/index.php? $\mathrm{r}=$ clima/normaisClimatologicas $>$. Acesso em abril de 2019.

KALNAY, E. et al. The NCEP/NCAR 40-year reanalysis project. Bulletin of the American Meteorological Society, Boston, v. 77, n. 3, p. 437-471, 1996.

KÖPPEN,W.; GEIGER,R. Klimate der Erde. Gotha: Verlag Justus Perthes. 1928.

MELO, A.B. C; CAVALCANTI,I.F.A; SOUZA,P.P. Zona de Convergência Intertropical do Atlântico. In: Tempo e Clima no Brasil. Org. CAVALCANTI,I.F.A et.al. São Paulo: Oficina de textos, 2009.

MOTA, F.S. Meteorologia Agrícola. São Paulo: Nobel, 1985.

PEGORIM, J. Como a ZCAS se forma? Climatempo, 2017. Disponível em: <https://www. climatempo.com.br/noticia/2017/11/17/como-a-zcas-se-forma--2964>. Acesso em junho de 2019.

ROLIM, G. S; SENTELHAS, P. C. Balanço hídrico normal por Thorntwaite e Mather (1955). Piracicaba: ESALQ/USP - Departamento de Ciências Exatas: Área de Física e Meteorologia, 1999.

THORNTHWAITE, C.W. An approach toward a rational classification of climate. Geographical Review, New York, n.1, p. 55-94, 1948.

THORNTHWAITE, C. W.; MATHER, J. R. The water balance. Publications in Climatology. New Jersey, Drexel Institute of Technology, 104p. 1955. 